\title{
Percutaneous mitral repair: current and future devices
}

\author{
Rodrigo Estévez-Loureiro ${ }^{1}$, Tomás Benito-González ${ }^{2}$, Carmen Garrote-Coloma ${ }^{2}$, \\ Felipe Fernández-Vázquez ${ }^{2}$, Pablo Avanzas ${ }^{3,4}$, Miguel Piñón ${ }^{5}$, Isaac Pascual ${ }^{3,4}$ \\ ${ }^{1}$ Interventional Cardiology Unit, Hospital Álvaro Cunqueiro, Vigo, Spain; ${ }^{2}$ Interventional Cardiology Unit, Complejo Asistencial Universitario \\ de Leon, Spain; ${ }^{3}$ Interventional Cardiology Unit, Área del Corazón, Hospital Universitario Central de Asturias, Oviedo, Spain; ${ }^{4}$ Instituto de \\ Investigación Sanitaria del Principado de Asturias, Oviedo, Asturias, Spain; ${ }^{5}$ Cardiac Surgery Department, Hospital Álvaro Cunqueiro, Vigo, Spain \\ Contributions: (I) Conception and design: R Estévez-Loureiro, C Garrote-Coloma, T Benito-González; (II) Administrative support: I Pascual; (III) \\ Provision of study materials or patients: R Estévez-Loureiro, F Fernández-Vázquez; (IV) Collection and assembly of data: P Avanzas, M Piñon, R \\ Estévez-Loureiro; (V) Data analysis and interpretation: R Estévez-Loureiro, T Benito-González; (VI) Manuscript writing: All authors; (VII) Final \\ approval of manuscript: All authors. \\ Correspondence to: Rodrigo Estévez-Loureiro, MD, PhD, FESC. Interventional Cardiology Unit, Hospital Álvaro Cunqueiro, c/ Clara Campoamor \\ 341, 36312 Vigo, Spain. Email: roiestevez@hotmail.com.
}

\begin{abstract}
Mitral regurgitation (MR) is the second most common valvular heart disease and its prevalence is increasing with population ageing. In the recent years we have witnessed the development of several transcatheter devices to correct MR in patients at high-risk for surgery. The majority of evidence regarding safety and efficacy of this new therapy comes from MitraClip studies. However, new alternatives on the field of valve repair have emerged with promising results. The aim of this review is to portrait the landscape of transcatheter mitral repair alternatives, from currently used devices to those that will have a role in the near future.
\end{abstract}

Keywords: Percutaneous mitral valve repair; transcatheter; mitral regurgitation (MR); heart failure

Submitted Dec 12, 2019. Accepted for publication Jan 20, 2020.

doi: 10.21037/atm.2020.03.154

View this article at: http://dx.doi.org/10.21037/atm.2020.03.154

\section{Introduction}

Mitral regurgitation (MR) is one of the most common symptomatic valvular disease worldwide (1). We can identify two main etiologies for MR. The degenerative MR (2-4) comprises several pathologies that involve anatomically mitral complex structures varying from simple chordal rupture (producing a scallop prolapse), to multi-segment prolapse in a valve with excess tissue and large annulus (also known as myxomatous valve). Functional MR (FMR) is secondary to $\mathrm{LV}$ remodeling, with left-chamber dilation and alteration of closing forces, with otherwise structurally preserved mitral structures. Significant MR is a common finding in patients with congestive heart failure (5) and is linked with an increased risk of cardiac adverse events (6-9). However, although the optimal management for FMR has still to be defined, a recent study with long follow-up has proved that medical management alone is associated with the highest rates of mortality (10). Mitral valve (MV) surgery has been the treatment of choice for severe MR if patients meet current guidelines' criteria (11). However, almost half of the patients $(12,13)$ referred for MV surgery are not intervened, predominantly due to $L V$ dysfunction, comorbidities or advanced age (14). Furthermore, the proportion of patients with FMR undergoing surgical treatment is even lower (15). The reason is two folds: the high-risk population and also to the fact that surgical interventions for FMR have shown an absence of prognostic benefit together with a high recurrence rate of significant MR (16-19). Likewise, FMR patients managed exclusively under medical therapy represent a high-risk population with increased rates of death and readmission due to heart failure (20). In this population catheter-based interventions have emerged to fill a large unmet need. 


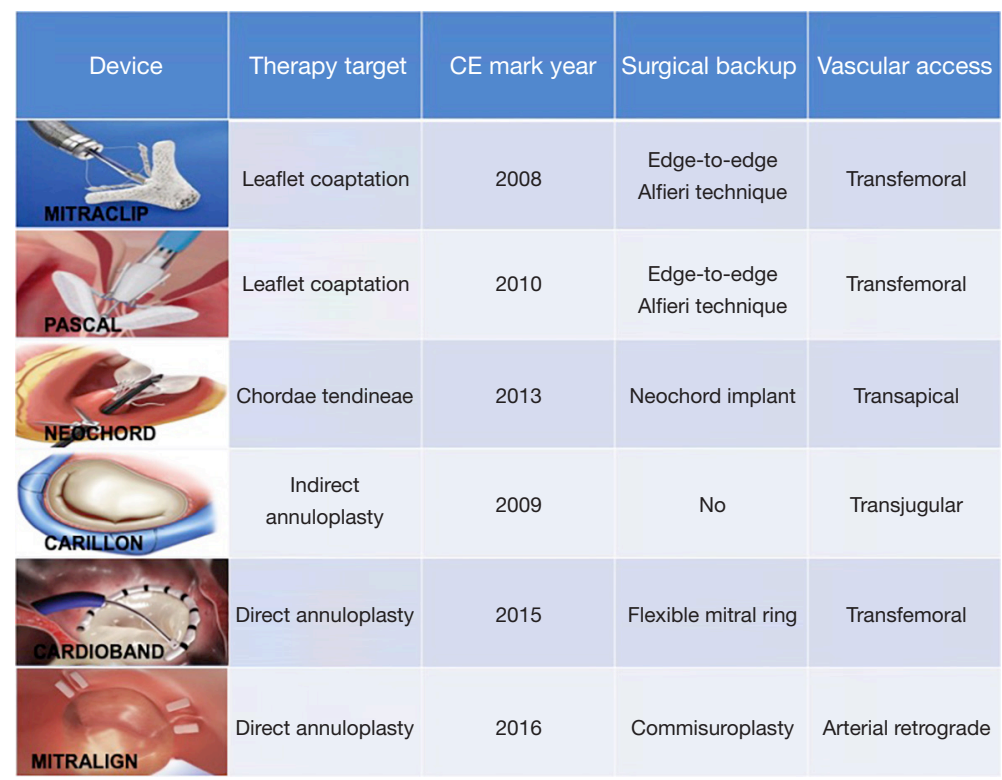

Figure 1 Current CE mark approved devices.

\section{Percutaneous MV repair}

The MV is an anatomical complex and its normal functioning depends on the preservation of all its components [leaflets, subvalvular apparatus, mitral annulus (MA)] and the LV normal shape. A lesion affecting any of these may lead to the development of MR (21). Several percutaneous devices have been developed, addressing different anatomical and pathophysiological targets involved in the MR genesis $(22,23)$.

Although facing some challenges (variable degrees of MR reduction, no applicable to all anatomies, addressing only one mechanism of MR at once, challenging interaction with MV structures) MV repair still poses several advantages over replacement techniques, such as, low complication rate, less invasive approach, less anatomical foot-print, very low risk of thrombosis and infection and almost all to date available evidence. These features support the idea that MV repair will have a predominant role in the future of transcatheter mitral interventions.

Percutaneous ongoing therapies have tried to replicate the concepts of any of the already open-surgery techniques, such as edge-to-edge repair (MitraClip ${ }^{\circledR}$, PASCAL $^{\circledR}$ ), ring annuloplasty $\left(\right.$ Carillon $^{\circledR}$, Cardioband $^{\circledR}$, Mitralign ${ }^{\circledR}$, Milliepede IRIS ${ }^{\circledast}$, Arto $^{\circledR}$, Amend $^{\circledR}$ ) or new chordal implantation $\left(\right.$ Neochord $^{\circledR}$ ). Some of them have been approved for human use and have been evaluated in clinical trials (Figure 1). Others are still in a very early phase and under investigation in early feasibility studies and are beyond the scope of this review (Accucinch, Mitral loop cerclage, Pipeline, MitralBridge, ChordArt, CardioMech. MitraClamp, Mitral Butterfly, Polares, Mitra Maze, Sutra). In the next lines we will discuss the most appealing devices used so far.

\section{Percutaneous edge-to-edge mitral valve repair (PMVR)}

\section{MitraClip ${ }^{\circledR}$}

The MitraClip ${ }^{\circledR}$ system (Abbott Vascular, IL, USA) the first device that have gained widespread clinical application, with a cumulative experience of $>100,000$ cases performed worldwide. This device consists of two clip arms and opposing grippers, which can be opened and closed against each other in order to grasp and gain cooptation of $M V$ leaflets at the origin of the regurgitant jet. The procedure is usually carried out under general anesthesia and using transesophageal echo and fluoroscopic guidance. Once the device is positioned over the desired zone to treat, the system is advanced across the MV into the LV. When the device is just below the leaflets the two arms are opened and the device is retracted to capture them and subsequently closed to increase the coaptation surface of the MV leaflets. The device can be reopened and repositioned all the times necessary in order to obtain the intended result. Subsequent clips can be added as required for achieving an optimal 

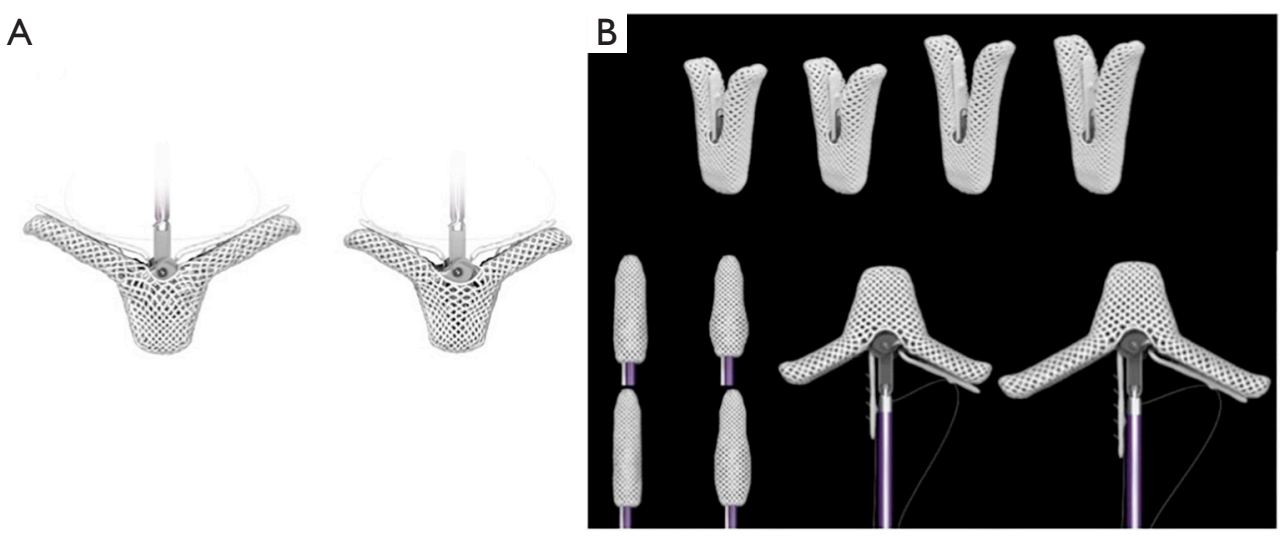

Figure 2 MitraClip device. (A) MitraClip XTR and NTR; (B) generation 4 (NTR, NTRW, XTR, XTRW). Reproduced with permission of Abbott Vascular (all rights reserved).

Table 1 Clip size selection chart

\begin{tabular}{llc}
\hline Variables & Anatomical considerations & Favored XTR \\
\hline Leaflet insertion & Longer leaflet & + \\
& A2-P2 & + \\
& Large flail & + \\
& Redundant leaflet & + \\
& Restricted leaflet & + \\
Tissue quality & More than mild calcification of annulus and leaflet & + \\
Gradient & Smaller MV area & + \\
Cordial entrapment & Mitral valve commissures & + \\
\hline
\end{tabular}

+ , preference. MV, mitral valve.

MR reduction. The amount of remainder leaflet tissue and the resulting increase in transmitral gradient are the main procedural limitations for further clip deployment. We are currently working with the $3 \mathrm{rd}$ generation of the device with two clip sizes available, one short (NTR) and one with long clip arms (XTR) (Figure 2A). Both have increased maneuverability, working length and position predictability. Information regarding their clinical use has come from the EXPAND registry, with excellent outcomes regarding MR reduction at 30 days (24) achieving MR less or equal to 1+ in almost $80 \%$ of this all-comers population. A guide to select de clip type is summarized in Table 1 .

MitraClip ${ }^{\circledR}$ repair has proven to be a safe and effective technique in patients with either functional or degenerative MR. Early feasibility of the therapy with MitraClip ${ }^{\circledR}$ was first demonstrated in the EVEREST I trial (25) and subsequently compared with conventional surgery in the randomized controlled trial (RCT) EVEREST II (26). In these studies, very stringent echo criteria were used to select the anatomic feasibility of device implantation. However, in real world, with increasing experience, a more complex range of valve pathologies can be treated with excellent results (27).

The majority of clinical evidence in the field of percutaneous MV treatment is related to $\mathrm{MitraClip}^{\circledR}$ and it is currently the most advanced available technology for clinical use. In the EVEREST II trial, 184 patients were randomized in a 2:1 fashion to receive MitraClip ${ }^{\circledR}$ and 95 patients to undergo surgical MV treatment (repair or replacement). The device was safer than surgery with a significant reduction of major adverse events (9.6\% vs. 57\% with surgery, $\mathrm{P}<0.0001$ ), mainly driven by a greater need for 
Table 2 Main registries on MitraClip

\begin{tabular}{|c|c|c|c|c|c|c|}
\hline Study & Type of study & $\begin{array}{l}\text { Number of patients } \\
\text { treated with MitraClip }\end{array}$ & $\begin{array}{c}\text { Location } \\
\text { [number of sites] }\end{array}$ & Enrollment years & Functional MR (\%) & $\begin{array}{l}\text { Procedural success } \\
\qquad(\mathrm{MR} \leq 2+)(\%)\end{array}$ \\
\hline Everest I & Feasibility trial & 24 & USA [11] & 2003-2005 & 21 & 74 \\
\hline Everest II HR & Registry & 351 & USA [38] & 2007-2014 & 70.1 & 85.8 \\
\hline SENTINEL & Registry & 628 & Europe [25] & 2011-2012 & 72 & 95.4 \\
\hline TRAMI & Registry & 1,064 & Germany [20] & 2010-2013 & 71 & 95.2 \\
\hline STS/ACC TVT & Registry & 564 & USA [61] & 2013-2014 & 14 & 93 \\
\hline
\end{tabular}

blood transfusion in the surgical arm. Conversely, the device proved to be less efficacious. In the intent to treat analysis, survival free from the primary endpoint (death, MV surgery and $\mathrm{MR}>2+$ ) was lower with MitraClip ${ }^{\circledR}$ as compared with surgery ( $55 \%$ vs. $73 \%, \mathrm{P}=0.0007)$ (26). However, no differences in mortality were observed. Results of this trial at 5 years follow up confirmed the initial results of the study, with no differences in mortality or reoperation between the PMVR arm and surgery, in those patients with an initial successful repair. The proportion of patients with significant MR at 5-year follow-up was $19 \%$, just the same observed at 1 year, reassuring the durability of the PMVR (28). Interestingly, although the proportion of patients with DMR included was greater, in the subgroup of patients with LVD and/or FMR, no differences in the primary endpoint were observed between the two groups, opening a new niche for PMVR. In fact, most of the subsequent observational studies have mainly included patients with FMR (Table 2) (29-34). Real-world registries showed high rates of procedural success (90-95\%), very low short-term adverse events and consistent improvements in symptoms, quality of life and a durable MR reduction.

However, only recently two randomized controlled trials have shed light into the controversial field of the FMR treatment. The clinical studies MITRA-FR (35) and COAPT (36) are the very first two studies that randomized patients with FMR to receive optimal medical therapy or optimal medical therapy plus edge-to-edge repair MitraClip $^{\circledR}$. The two trials showed conflicting results. In the MITRA-FR the device did not produce any benefits over the composite event of death or rehospitalizations after one year of follow-up. On the contrary, in the COAPT trial, the device showed a significant reduction of the number of hospitalizations after 2 years of follow-up, and a reduced composite endpoint of death/rehospitalizations. It seems reasonable to try to analyze the differences between both studies in an attempt to understand these opposing findings. Main differences between trials are shown in Table 3.

The interesting thing about these studies is that they should be considered together and see them as complementary. We have to be cautious with patients in very advanced stages of HF (greater ventricular dilation, severe irreversible pulmonary hypertension, frequent use of inotropes), with non-severe FMR or without optimal medical therapy. If we want to replicate the positive results of COAPT, our candidates need to be in the early stages of the disease, have a significant degree of FMR [that really contributes to the clinical situation (37)], be correctly treated at the maximum tolerated drug dosages, and have good results with the device (anatomical selection and the experience of the interventional team plays a key role). Interestingly, on top of reducing major events, subanalyses of COAPT have shown that MitraClip also improves quality of life and functional class (38). We should take into account these effects when selecting patients because this may be the only therapy that will alleviate very advanced symptoms. And regarding patients with advanced HF, COAPT showed as well that MitraClip can lead to a reduction in the heart transplant or LVAD implantation rate. This finding, together with other positive data coming from registries, such as reverse remodeling, decrease in arrhythmic burden or improvement in $\mathrm{O}_{2}$ consumption may prompt the indication in patients with LVD and advanced heart failure (36,39-42). 
Table 3 Main differences between MITRA-FR and COAPT trials

\begin{tabular}{lll}
\hline Variables & MiTRA.FR $(\mathrm{n}=304)$ & COAPT $(\mathrm{n}=614)$ \\
\hline Severity FMR & ESC Guidelines: ERO $>20 \mathrm{~mm}^{2}$ or RV $>30 \mathrm{~mL} /$ beat & US Guidelines: ERO $>30 \mathrm{~mm}{ }^{2}$ or RV $>45 \mathrm{~mL} / \mathrm{beat}$ \\
& Mean ERO $31 \pm 10 \mathrm{~mm}^{2}$ & Mean ERO $41 \pm 15 \mathrm{~mm}^{2}$ \\
& Mean LVEDVI $135 \pm 35 \mathrm{~mL} / \mathrm{m}^{2}$ & Mean LVEDVI $101 \pm 34 \mathrm{~mL} / \mathrm{m}^{2}$ \\
GMDT at baseline and FU & Allowing adjustment in a 'real-world fashion' & Confirmed by CEC 'maximal tolerated GMDT'. Few \\
& $9 \%$ & changes FU \\
AP failure & $14.5 \%$ & $5 \%$ \\
Procedural complications & $17 \%$ & $8.5 \%$ \\
MR $\leq 2+12$ mo & No & $5 \%$ \\
$\begin{array}{l}\text { Exclusion for poor clinical } \\
\text { features }\end{array}$ & & Severe PHT \\
& & Right ventricular mod/sev failure \\
& & HF stage D \\
Hospitalizations previous year & All & HD instability or inotropes \\
\hline
\end{tabular}

AP, acute procedural; CEC, eligibility committee; ERO, effective regurgitant orifice; FU, follow up; GDMT, guideline directed medical therapy; HD, hemodynamic instability; HF, heart failure; LVEDVI, left ventricular end-diastolic volume index; MR, mitral regurgitation; PHT, pulmonary hypertension; RV, regurgitant volume.

A

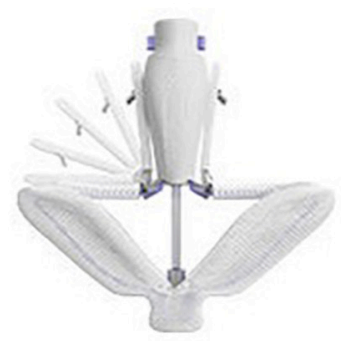

Figure 3 PASCAL device. Reproduced with permission.

\section{Future developments}

Following COAPT results it is clear that a reduction of residual MR to the minimum must be a goal with this therapy to maintain the clinical benefit. In order to achieve that standard, in a few months the Generation 4 will be available (Figure 2B). Main characteristics of this evolution will be the possibility of independent grasping, the availability of 4 clip sizes (the 2 NTR and XTR and the wide version of both, NTRW, XTRW), the continuous LA pressure monitoring and the easier deployment. All these features are intended to provide an easier and safer procedure, increasing the procedural success with a single clip and allowing a tailored
B

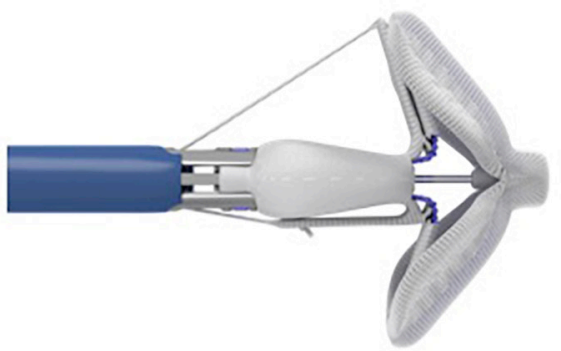

approach for both, DMR and FMR.

\section{PASCAL $^{\circledR}$}

The PASCAL ${ }^{\circledR}$ device (Edwards Lifesciences, Irvine, California) is a transcatheter device for the transseptal leaflet repair of a leaking $M V$ through increasing leaflet coaptation by tissue approximation with an anatomic spacer (Figure 3). The device is composed of 2 broad paddles, 2 clasps capable of independent movement (similar to grippers), and a nitinol woven spacer that allows improved leaflet capture, to reduce valve regurgitation while minimizing stress on the native valve leaflets. The complete system is $22 \mathrm{Fr}$ and 

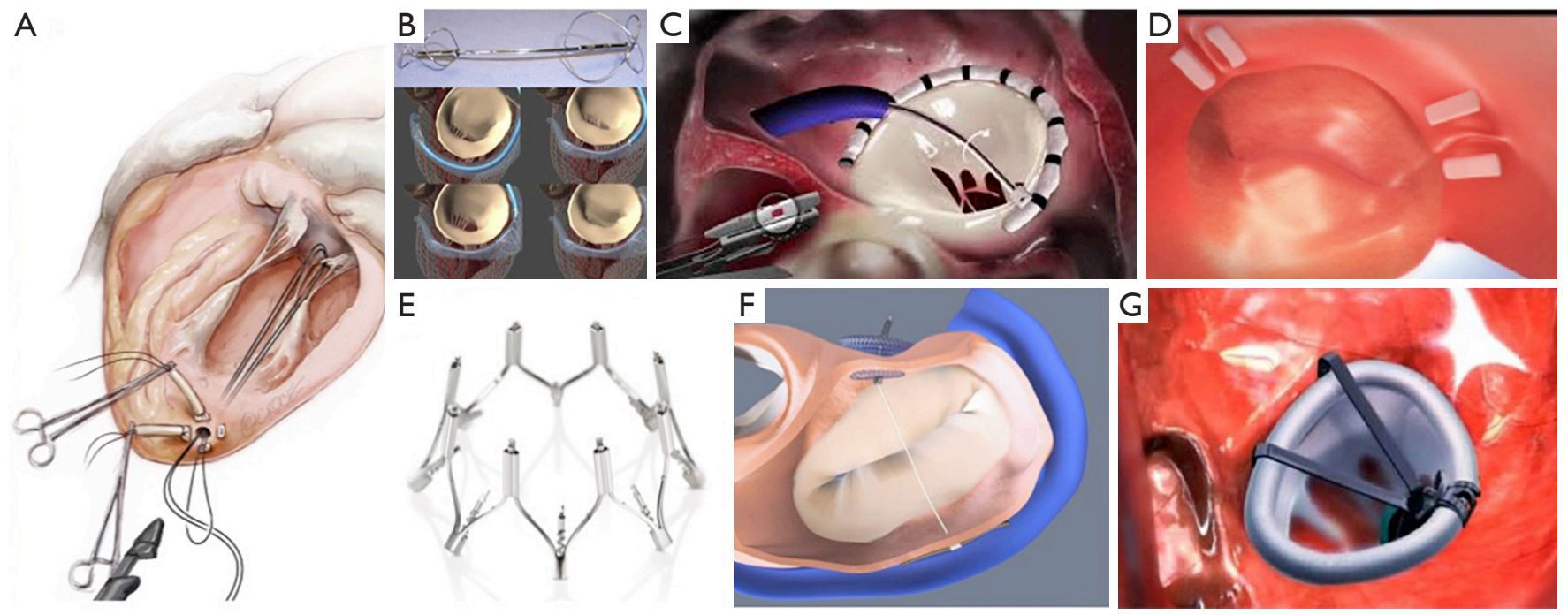

Figure 4 New devices for transcatheter mitral valve repair. (A) Carillon; (B) Cardioband; (C) Mitralign; (D) Neochord; (E) Millipede IRIS (reproduced with permission of Boston Sci.); (F) ARTO device; (G) Amend ring. Reproduced with permission.

the device can be completely elongated which favors the interaction with the subvalvular apparatus. The device has been evaluated in the CLASP registry (43). In this study 62 patients were treated with the device. MR was secondary in $56 \%$ of cases. At 30 days the MR was grade 2 or less in $98 \%$ of the patients and $85 \%$ were in functional class I-II. In addition, a significant improvement was observed in the 6-minute test and in the quality of life questionnaires. Several trials are under way with the device including direct comparisons with MitraClip in both DMR and FMR (CLASP IID/IIF Pivotal Clinical Trial, NCT03706833).

\section{Percutaneous chordal replacement}

\section{Neochord $^{\circledR}$}

Neochord $^{\circledR}$ (Neochord, Minnesota, MN) are the first ePTFE chordal loops conceived to be implanted on the MV leaflets to correct flail or prolapse (Figure 4A) (44). Colli et al. reported the results of transapical implantation of Neochord in 62 patients with MV prolapse (45). Thirty-day major adverse events included 1 acute myocardial infarction (2\%) and 2 cases of sepsis (3\%). MR at 30 days was equal or less than $2+$ in $88.7 \%$ of patients. Interestingly, a classification in 3 groups (from A-single P2 prolapse/flail- to C-paracommissural disease, annular and leaflet calcifications-) of increasing complexity has been created in order to predict device success. In the early European experience, 213 patients were included (46). The number of Type A, B and C patients was $82(38.5 \%), 98(46 \%)$ and $33(15.5 \%)$, respectively. Procedural success was achieved in 206 (96.7\%) patients, with an in-hospital mortality of $1.9 \%$. At 1 year, MR was severe in $7.9 \%$ with significant differences between groups (A $4 \%$, B $9 \%$, C $22 \%)$. This fact, together with the absence of annular treatment, underscores de importance of anatomical patient selection in order to achieve optimal results.

\section{Transcatheter mitral valve annuloplasty (TMVA)}

Annuloplasty is the most common surgical repair performed to treat MR following the 3 principles of surgical MV repair: preserve leaflet mobility, increase leaflet coaptation surface and avoid progressive annular dilation (47). This technique is widely used as a stand-alone procedure in FMR or added to leaflet repair or chordal implantation in degenerative MR (48). Some percutaneous devices have tried to reproduce undersized MV annuloplasty to address dilatation of the MA. TMVA has the potential to improve outcomes in combination with edge-to-edge repair in selected patients and to increase therapeutic alternatives in patients with anatomic ineligibility for edge-to-edge repair. Another potential advantage this approach is that it preserves the native valve anatomy, allowing the possibility for future valve implantation.

\section{Carillon ${ }^{\circledR}$}

The coronary sinus (CS) is in close relationship with two 
thirds of the MA, in close relation to the posterior MV leaflet. This was the rationale behind the first catheter-based devices that aim to create an indirect annuloplasty effect through the CS. The Carillon ${ }^{\circledR}$ Mitral Contour System (Figure 4B; Cardiac Dimension, Inc., Kirkland, WA, USA) obtained the CE mark in 2011. This device is implanted in the CS and reducing the septolateral diameter of the MA by post-implant device shortening (49). The procedure is carried out under fluoroscopic guidance through a jugular vein access and without general anesthesia. Nevertheless, there are some limitations that have hampered the development of this technique. First, CT imaging studies have shown that the location of the CS is no coplanar to the MA, but in a more basal position (50). Second, there have been reported serious complications, such as compression of the circumflex artery or damage of the septal conduction system (51). Finally, there is no prior surgical background for the CS approach, so the long-term results are largely unknown.

Published evidence comprised 2 observational studies and a randomized trial. In the Titan trial, only 36 of 53 patients received permanent system implantation due to transient coronary compromise (recapture of the device was carried out in those cases) (52). Mortality at 1 and 12 months in this trial were $1.9 \%$ and $22.6 \%$. In the TITAN II trial, the implant success was achieved in $83.3 \%$ patients, and 1-month and 1-year reported mortality were $2.8 \%$ and $23 \%$, respectively. Both trials showed a significant reduction in MR, and clinical improvement and reverse $L V$ remodeling in patients with FMR during 2-year followup. Finally, REDUCE-FMR RCT compared the device to OMT in HF subjects with FMR, in a sham-based study (53). One hundred twenty patients were allocated to the device $(n=87)$ or medical treatment $(n=33)$. The study showed a statistically significant reduction in mitral regurgitant volume in the treatment group compared to the control group and a significant inverse LV remodeling as well. However, no differences in clinical end-points were noted, although the trial was underpowered for such findings.

\section{Cardioband $^{\circledR}$}

Cardioband $^{\circledR}$ (Edwards Lifesciences, Irvine, CA) is a transcatheter device that resembles surgical incomplete direct annuloplasty technique (Figure $4 C$ ). The system consists of a flexible Dacron band of different sizes delivered from a transseptal approach and implanted onto the atrial side of the MA, starting from anterolateral commissure. The band is attached in a supraannular position with multiple screws from commissure to commissure under transesophageal echo and fluoro guide. After implantation, the band length is shortened through a cinching tool in order to increase leaflet coaptation and reduce MR.

Although surgical experience with flexible incomplete rings was disappointing (54), initial clinical experiences with Cardioband ${ }^{\circledR}$ are promising (55). The CE Mark Trial enrolled high-risk subjects with symptomatic FMR and annular dilation. Early outcomes of this trial in 31 patients at 1 month showed a significant reduction in the septolateral dimension of the MA $(36.8 \pm 4.8 v s .29 \pm 5.5 \mathrm{~mm}$, $\mathrm{P}<0.01)$ and an increased leaflet coaptation surface (56). Following Cardioband ${ }^{\circledR}$ shortening, MR was none or trace in $6(21 \%)$, mild in $21(72 \%)$ and moderate in $2(7 \%)$ cases. No procedural mortality was noted, although in-hospital mortality was $6.5 \%$ (neither procedure- nor device-related). At 30 days, 22 of the 25 patients (88\%) had MR grade $\leq 2+$. Following results of this trial showed persistent reduction in MR (92\% MR $\leq 2+)$ and improvement in functional class (77\% NYHA I-II) at 24 months follow up. The results are maintained at 1-year follow-up, with persistent reduction on MR grade and in the MA dimensions and with improvement in clinical status (57).

\section{Mitralign $^{\circledR}$}

The Mitralign $^{\circledR}$ (Mitralign, Inc., Tewksbury, MA, USA) is a transcatheter direct annuloplasty system that mimics the Kay-Wooler commissuroplasty (Figure 4D) (58). The device allows the plication of the medial and lateral aspects of the MA by deploying pairs of transannular "pledgets". The procedure is carried out from a transfemoral retrograde approach under live echo and fluoroscopic guidance. Each pledget pair is pulled together resulting in a segmental posterior annuloplasty (59). In the CE Mark Trial, the system was successfully implanted in $70.4 \%$ of 71 patients with FMR (60). No intraprocedural death occurred, but $8.9 \%$ patients experienced cardiac tamponade. Thirty-day and 6-month reported all-cause mortality were $4.4 \%$ and $12.2 \%$, respectively. Significant improvements in clinical functional class, reduction in MA dimensions, and LV remodeling were demonstrated at 6 months. However, magnitude of MR reduction is not comparable previously described devices and remodeling of the MA is restricted to small areas, thus making this device less appealing.

\section{Millipede $^{\circledR}$}

The Millipede IRIS annuloplasty device (Millipede, Inc., Santa Rosa, CA) is a semirigid, nitinol-framed, complete 
ring (Figure 4E). Eight helical stainless-steel anchors are preattached to the base of the ring and they are used to attach the ring to the MA. The upper part of the device has 8 sliding collars that can be manipulated individually. When put under tension, each collar draws the two adjacent helical anchors closer together and this fact allows operators to customize the final annular shape and diameter. Limited clinical experience has been achieved so far, but it can be safely delivered through transseptal approach with significant reduction in MA dimensions and the degree of MR (61). Interestingly, new iterations of the device integrate an intracardiac echo probe that allows better visualization of cardiac structures for safe anchor placement.

\section{Arto $^{\circledR}$}

The ARTO system (MVRx Inc., Belmont, CA, USA) is comprised of two anchors deployed over the lateral wall of the left atrium via the CS and in the atrial septum, connected by a tether that traverses the left atrial chamber (Figure 4F). The idea is to deliver a coronary sinus anchor (T-bar) and an atrial septal anchor, connected by a suture whose length can be adjusted to reduce the anteroposterior (AP) annular diameter until an acceptable reduction in MR is achieved. In the Mitral Valve Repair Clinical Trial (MAVERIC) authors presented the early phase (30 days) outcome of 11 patients that were treated with the ARTO system. Effective regurgitant orifice area decreased from $30.3 \pm 11.1$ to $13.5 \pm 7.1 \mathrm{~mm}^{2}$, and regurgitant volumes from $45.4 \pm 15.0$ to $19.5 \pm 10.2 \mathrm{~mL}$. The mitral annular anteroposterior diameter decreased from $45.0 \pm 3.3$ to $38.7 \pm 3.0 \mathrm{~mm}$. Regarding safety issues at 30 days, no major adverse events were reported, but one patient experienced pericardial effusion and there was one asymptomatic device dislodgment (62).

\section{Amend $^{\circledR}$}

Valcare Amend system (Valcare Medical; Israel) is a complete, semi-rigid D-shaped transcatheter annuloplasty system (Figure 4G). The device can be delivered through a transapical or a transseptal approach. The device is anchored first in the posterior annulus and then approaches de anterior aspect. It has been used in cases as a stand-alone therapy or in combination with Neochord or MitraClip with relevant reduction of the regurgitant jet area and in the anteroposterior diameter (63).

\section{Transcatheter multimodal approach for MR}

Cardiac surgery has taught us that combination of diverse techniques addressing different mechanisms of MR may improve long-term outcomes (48). In this sense, there has been reported the first series of device combination therapy. Recently, experiences of direct and indirect TMVA after failure of PMVR with MitraClip ${ }^{\circledR}$ have been published (64-66). MitraClip ${ }^{\circledR}$ is currently the most widespread technique focus on MV leaflets, with contrasted effective results. Nevertheless, reported recurrence of significant MR may surpass $20 \%$ at 1 year (29), when applied to an allcomers population. Notably, transcatheter mitral rings may play a role as valuable adjunct catheter-based procedures to Mitraclip ${ }^{\circledR}$ or PASCAL ${ }^{\circledR}$ (or percutaneous chordal replacement) in selected patients (such as very dilated LA and MA).

\section{Conclusions}

There is a huge technological development in the field of PMVR. Due to their clinical and anatomical advantages, these repair systems will have an important role in the treatment of MR. MitraClip is so far the most established device with the broader body of evidence. Future generation devices will help to refine and expand the transcatheter repair possibilities.

\section{Acknowledgments}

Funding: None.

\section{Footnote}

Provenance and Peer Review: This article was commissioned by the Guest Editor (Daniel Hernández-Vaquero) for the series"Structural Heart Disease: The Revolution"published in Annals of Translational Medicine. The article was sent for external peer review organized by the Guest Editor and the editorial office.

Conflicts of Interest: All authors have completed the ICMJE uniform disclosure form (available at http://dx.doi. org/10.21037/atm.2020.03.154). The series "Structural Heart Disease: The Revolution" was commissioned by the editorial office without any funding or sponsorship. REL has received research grant and speaker fees from Abbott Vascular. The authors have no other conflicts of interest to declare.

Ethical Statement: The authors are accountable for all 
aspects of the work in ensuring that questions related to the accuracy or integrity of any part of the work are appropriately investigated and resolved.

Open Access Statement: This is an Open Access article distributed in accordance with the Creative Commons Attribution-NonCommercial-NoDerivs 4.0 International License (CC BY-NC-ND 4.0), which permits the noncommercial replication and distribution of the article with the strict proviso that no changes or edits are made and the original work is properly cited (including links to both the formal publication through the relevant DOI and the license). See: https://creativecommons.org/licenses/by-ncnd/4.0/.

\section{References}

1. Nkomo VT, Gardin JM, Skelton TN, et al. Burden of valvular heart diseases: a population-based study. Lancet 2006;368:1005-11.

2. Carpentier A. Cardiac valve surgery--the "French correction". J Thorac Cardiov Surg 1983;86:323-37.

3. Adams DH, Rosenhek R, Falk V. Degenerative mitral valve regurgitation: best practice revolution. Eur Heart J 2010;31:1958-66.

4. Barlow JB, Pocock WA. The significance of late systolic murmurs and mid-late systolic clicks. Md State Med J 1963;12:76-7.

5. Bursi F, Barbieri A, Grigioni F, et al. Prognostic implications of functional mitral regurgitation according to the severity of the underlying chronic heart failure: a long-term outcome study. Eur J Heart Fail 2010;12:382-8.

6. Bursi F, Enriquez-Sarano M, Nkomo VT, et al. Heart failure and death after myocardial infarction in the community: the emerging role of mitral regurgitation. Circulation 2005;111: 295-301.

7. Robbins JD, Maniar PB, Cotts W, et al. Prevalence and severity of mitral regurgitation in chronic systolic heart failure. Am J Cardiol 2003;91: 360-2.

8. Trichon BH, Felker GM, Shaw LK, et al. Relation of frequency and severity of mitral regurgitation to survival among. Am J Cardiol 2003;91:538-43.

9. Grigioni F, Enriquez-Sarano M, Zehr KJ, et al. Ischemic mitral regurgitation: long-term outcome and prognostic implications with quantitative Doppler assessment. Circulation 2001;103:1759-64.

10. Castleberry AW, Williams JB, Daneshmand MA, et al. Surgical revascularization is associated with maximal survival in patients with ischemic mitral regurgitation: a 20-year experience. Circulation 2014;129:2547-56.

11. Vahanian A, Alfieri O, Andreotti F, et al. Guidelines on the management of valvular heart disease. Eur Heart J 2012;33:2451-96.

12. Mirabel M, Iung B, Baron G, et al. What are the characteristics of patients with severe, symptomatic, mitral. Eur Heart J 2007;28:1358-65.

13. Borger MA, Alam A, Murphy PM, et al. Chronic ischemic mitral regurgitation: repair, replace or rethink? Ann Thorac Surg 2006;81:1153-61.

14. Jamieson WR, Edwards FH, Schwartz M, et al. Risk stratification for cardiac valve replacement. National Cardiac Surgery. Ann Thorac Surg 1999;67:943-51.

15. Bach DS, Awais M, Gurm HS, et al. Failure of guideline adherence for intervention in patients with severe mitral regurgitation. J Am Coll Cardiol 2009;54:860-5.

16. Wu AH, Aaronson KD, Bolling SF, et al. Impact of mitral valve annuloplasty on mortality risk in patients with mitral regurgitation and left ventricular systolic dysfunction. J Am Coll Cardiol 2005; 45: 381-7.

17. Hung J, Papakostas L, Tahta SA, et al. Mechanism of recurrent ischemic mitral regurgitation after annuloplasty: continued $\mathrm{LV}$ remodeling as a moving target. Circulation 2004;110: III5-90.

18. McGee EC, Gillinov AM, Blackstone EH, et al. Recurrent mitral regurgitation after annuloplasty for functional ischemic mitral regurgitation. J Thorac Cardiovasc Surg 2004;128:916-24.

19. Acker MA, Parides MK, Perrault LP, et al. Mitral-valve repair versus replacement for severe ischemic mitral regurgitation. N Engl J Med 2014;370:23-32.

20. Goel SS, Bajaj N, Aggarwal B, et al. Prevalence and outcomes of unoperated patients with severe symptomatic mitral regurgitation and heart failure: comprehensive analysis to determine the potential role of MitraClip for this unmet need. J Am Coll Cardiol 2014;63:185-6.

21. Dal-Bianco JP, Beaudoin J, Handschumacher MD, et al. Basic mechanisms of mitral regurgitation. Can J Cardiol 2014;30:971-81.

22. Estevez-Loureiro R, Franzen O. Current state of percutaneous transcatheter mitral valve therapies. Panminerva Med 2013;55:327-37.

23. Herrmann HC, Maisano F. Transcatheter therapy of mitral regurgitation. Circulation 2014;130:1712-22.

24. Von Bardeleben RS. Contemporary, real-world, clinical outcomes with the next generation MitraClip ${ }^{\mathrm{TM}}$ (NTR/ XTR) System: Results from the 1000+ patient global 
EXPAND Study. European Society of Cardiology

Congress. Paris, FR. (2019).

25. Feldman T, Wasserman HS, Herrmann HC, et al. Percutaneous mitral valve repair using the edge-to-edge technique: six-month results of the EVEREST Phase I Clinical Trial. J Am Coll Cardiol 2005;46:2134-40.

26. Feldman T, Foster E, Glower DD, et al. Percutaneous repair or surgery for mitral regurgitation. N Engl J Med 2011;364:1395-406.

27. Boekstegers P, Hausleiter J, Baldus S, et al. Percutaneous interventional mitral regurgitation treatment using the Mitra-Clip system. Clin Res Cardiol 2014;103:85-96.

28. Feldman T, Kar S, Elmariah S, et al. Randomized Comparison of Percutaneous Repair and Surgery for Mitral Regurgitation: 5-Year Results of EVEREST II. J Am Coll Cardiol 2015;66:2844-54.

29. Maisano F, Franzen O, Baldus S, et al. Percutaneous mitral valve interventions in the real world: early and 1-year results from the ACCESS-EU, a prospective, multicenter, nonrandomized post-approval study of the MitraClip therapy in Europe. J Am Coll Cardiol 2013;62:1052-61.

30. Sürder D, Pedrazzini G, Gaemperli O, et al. Predictors for efficacy of percutaneous mitral valve repair using the MitraClip system: the results of the MitraSwiss registry. Heart 2013;99:1034-40.

31. Nickenig G, Estevez-Loureiro R, Franzen O, et al. Percutaneous Mitral Valve Edge-to-Edge Repair: InHospital Results and 1-Year Follow-Up of 628 Patients of the 2011-2012 Pilot European Sentinel Registry. J Am Coll Cardiol 2014;64:875-84.

32. Schillinger W, Hunlich $M$, Baldus S, et al. Acute outcomes after MitraClip therapy in highly aged patients: results from the German TRAnscatheter Mitral valve Interventions (TRAMI) Registry. EuroIntervention 2013;9:84-90.

33. Puls M, Lubos E, Boekstegers P, et al. One-year outcomes and predictors of mortality after MitraClip therapy in contemporary clinical practice: results from the German transcatheter mitral valve interventions registry. Eur Heart J 2016;37:703-12.

34. Sorajja P, Mack M, Vemulapalli S, et al. Initial Experience With Commercial Transcatheter Mitral Valve Repair in the United States. J Am Coll Cardiol 2016;67:1129-40.

35. Obadia JF, Messika-Zeitoun D, Leurent G, et al. Percutaneous Repair or Medical Treatment for Secondary Mitral Regurgitation. N Engl J Med 2018;379:2297-306.

36. Stone GW, Lindenfeld J, Abraham WT, et al. Transcatheter Mitral-Valve Repair in Patients with Heart
Failure. N Engl J Med 2018;379:2307-18.

37. Asch FM, Grayburn PA, Siegel RJ, et al. Echocardiographic Outcomes after Transcatheter Leaflet Approximation in Patients with Secondary Mitral Regurgitation: The COAPT Trial. J Am Coll Cardiol 2019;74:2969-79.

38. Arnold SV, Chinnakondepalli KM, Spertus JA, et al. Health Status After Transcatheter Mitral-Valve Repair in Heart Failure and Secondary Mitral Regurgitation: COAPT Trial. J Am Coll Cardiol 2019;73:2123-32.

39. Geis N, Raake P, Lewening M, et al. Percutaneous repair of mitral valve regurgitation in patients with severe heart failure: comparison with optimal medical treatment. Acta Cardiol 2018;73:378-86.

40. Pleger ST, Schulz-Schonhagen M, Geis N, et al. One year clinical efficacy and reverse cardiac remodelling in patients with severe mitral regurgitation and reduced ejection fraction after MitraClip implantation. Eur J Heart Fail 2013;15:919-27.

41. Benito-González T, Estevez-Loureiro R, Garrote-Coloma C, et al. Effect of Successful Edge-to-Edge Mitral Valve Repair on Ventricular Arrhythmic Burden in Patients With Functional Mitral Regurgitation and Implantable Cardiac Devices. Am J Cardiol 2019;124:1113-9.

42. Benito-González T, Estevez-Loureiro R, Garrote-Coloma C, et al. MitraClip improves cardiopulmonary exercise test in patients with systolic heart failure and functional mitral regurgitation. ESC Heart Fail 2019;6:867-73.

43. Lim DS, Kar S, Spargias K, et al. Transcatheter Valve Repair for Patients With Mitral Regurgitation: 30-Day Results of the CLASP Study. JACC Cardiovasc Interv 2019;12:1369-78.

44. Seeburger J, Rinaldi M, Nielsen SL, et al. Off-pump transapical implantation of artificial neo-chordae to correct mitral regurgitation: the TACT Trial (Transapical Artificial Chordae Tendinae) proof of concept. J Am Coll Cardiol 2014;63:914-9.

45. Colli A, Bellu R, Pittarello D, et al. Transapical off-pump Neochord implantation on bileaflet prolapse to treat severe mitral regurgitation. Interact Cardiovasc Thorac Surg 2015;21:554-6.

46. Colli A, Manzan E, Aidietis A, et al. An early European experience with transapical off-pump mitral valve repair with NeoChord implantation. Eur J Cardiothorac Surg 2018;54:460-6.

47. Maisano F, Skantharaja R, Denti P, et al. Mitral annuloplasty. Multimed Man Cardiothorac Surg 2009;2009:mmcts.2008.003640.

48. De Bonis M, Lapenna E, Maisano F, et al. Long-term 
results ( $</=18$ years) of the edge-to-edge mitral valve repair without annuloplasty in degenerative mitral regurgitation: implications for the percutaneous approach. Circulation 2014;130:S19-24.

49. Schofer J, Siminiak T, Haude M, et al. Percutaneous mitral annuloplasty for functional mitral regurgitation: results of the CARILLON Mitral Annuloplasty Device European Union Study. Circulation 2009;120:326-33.

50. Maselli D, Guarracino F, Chiaramonti F, et al. Percutaneous mitral annuloplasty: an anatomic study of human coronary sinus and its relation with mitral valve annulus and coronary arteries. Circulation 2006;114:377-80.

51. Degen H, Schneider T, Wilke J, et al. Coronary sinus devices for treatment of functional mitral valve regurgitation. Solution or dead end? Herz 2013;38:490-500.

52. Siminiak T, Wu JC, Haude M, et al. Treatment of functional mitral regurgitation by percutaneous annuloplasty: results of the TITAN Trial. Eur J Heart Fail 2012;14:931-8.

53. Witte KK, Lipiecki J, Siminiak T, et al. The REDUCE FMR Trial: A Randomized Sham-Controlled Study of Percutaneous Mitral Annuloplasty in Functional Mitral Regurgitation. JACC Heart fail 2019;7:945-55.

54. Spoor MT, Geltz A, Bolling SF. Flexible versus nonflexible mitral valve rings for congestive heart failure: differential durability of repair. Circulation 2006;114:I67-71.

55. Maisano F, La Canna G, Latib A, et al. First-in-man transseptal implantation of a "surgical-like" mitral valve annuloplasty device for functional mitral regurgitation. JACC Cardiovasc Interv 2014;7:1326-8.

56. Maisano F, Taramasso M, Nickenig G, et al. Cardioband, a transcatheter surgical-like direct mitral valve annuloplasty system: early results of the feasibility trial. Eur Heart J 2016;37:817-25.

57. Messika-Zeitoun D, Nickenig G, Latib A, et al. Transcatheter mitral valve repair for functional mitral regurgitation using the Cardioband system: 1 year outcomes. Eur Heart J 2019;40:466-72.

Cite this article as: Estévez-Loureiro R, Benito-González T, Garrote-Coloma C, Fernández-Vázquez F, Avanzas P, Piñón M, Pascual I. Percutaneous mitral repair: current and future devices. Ann Transl Med 2020;8(15):963. doi: 10.21037/ atm.2020.03.154
58. Kay JH, Magidson O, Meihaus JE. The surgical treatment of mitral insufficiency and combined mitral stenosis and insufficiency using the heart-lung machine. Am J Cardiol 1962;9:300-6.

59. Siminiak T, Dankowski R, Baszko A, et al. Percutaneous direct mitral annuloplasty using the Mitralign Bident system: description of the method and a case report. Kardiol Pol 2013;71:1287-92.

60. Nickenig G, Schueler R, Dager A, et al. Treatment of Chronic Functional Mitral Valve Regurgitation With a Percutaneous Annuloplasty System. J Am Coll Cardiol 2016;67:2927-36.

61. Rogers JH, Boyd WD, Smith TW, et al. Transcatheter Mitral Valve Direct Annuloplasty with the Millipede IRIS Ring. Interv Cardiol Clin 2019;8:261-7.

62. Rogers JH, Thomas M, Morice MC, et al. Treatment of Heart Failure With Associated Functional Mitral Regurgitation Using the ARTO System: Initial Results of the First-in-Human MAVERIC Trial (Mitral Valve Repair Clinical Trial). JACC Cardiovasc Interv 2015;8:1095-104.

63. Meerkin D. The AMEND Mitral Repair System: Technology and Clinical Updates. Present. CRT 2019. Chicago, IL (2019)

64. Latib A, Ancona MB, Ferri L, et al. Percutaneous Direct Annuloplasty With Cardioband to Treat Recurrent Mitral Regurgitation After MitraClip Implantation. JACC Cardiovasc Interv 2016;9:e191-2.

65. Abdelrahman N, Chowdhury MA, Al Nooryani A, et al. A case of dilated cardiomyopathy and severe mitral regurgitation treated using a combined percutaneous approach of MitraClip followed by CARILLON(R) mitral contour system. Cardiovasc Revasc Med 2016;17:578-81.

66. Rogers JH, Boyd WD, Smith TWR, et al. Combined MitraClip Edge-to-Edge Repair With Millipede IRIS Mitral Annuloplasty. JACC Cardiovasc Interv $2018 ; 11: 323-4$. 